УДК 656.13

DOI: $10.21779 / 2500-1930-2018-33-4-37-44$

\title{
II.M. Исаева
}

\section{Анализ состояния и перспективы развития транспортного комплекса Республики Дагестан}

Дагестанский государственный университет; Россия, 367001, 2. Махачкала, ул. М. Гаджиева,43a; shamsi69@rambler.ru

В условиях трансформации экономики и необходимости ее развития под воздействием факторов продолжающегося кризиса, санкционного давления и глобализации транспортный комплекс становится ключевым фактором в достижении экономических и социальных целей страны, так как является объединяющим в единое экономическое пространство все регионы и различные отрасли народного хозяйства звеном, обеспечивающим их взаимную согласованную деятельность. Для решения проблем роста экономики региона как части экономики страны необходимо обеспечить слаженное функционирование всей инфраструктуры транспортной отрасли Дагестана, повысить качество и мобильность оказываемых ею услуг.

Исследование транспортного комплекса, его формирования, развития и содержания является многоаспектной и многогранной проблемой. Остановимся на основных аспектах воздействия состояния транспортной системы на экономическое развитие и качество жизни в регионе. Для этой цели в статье приводится исследование состояния структурных элементов транспортной отрасли Республики Дагестан, рассмотрен ряд вопросов ее функционирования и перспектив развития, проведен анализ статистических показателей за период с 2015 по 2017 гг., по результатам которого выявлена корреляционная связь состояния транспортного комплекса и экономики региона, обоснован тезис о первичности в указанной связи транспортной отрасли при реализации Транспортной стратегии Российской Федерации.

Ключевые слова: транспорт, экономика, анализ, инвестиция, динамика, мобильность, качество, инфраструктура, протяженность, отрасли.

Транспортная система является одной из важнейших составных частей инфраструктуры экономики страны, о чем свидетельствует ее удельный вес: в основных производственных фондах он составил на 2009 год 17,6 \%, в доле транспортных услуг в ВВП на 2007 год - 8\%, в инвестициях на развитие отраслей экономики на 2009 год $24,3 \%$, в численности занятых работников на 2009 год - 6,1\%, а также в потреблении энергоресурсов, металла и в ряде других важных показателей [10].

Транспортную систему можно определить как территориальную сеть путей сообщения, технических средств и служб перевозок, которая, объединяя все виды транспорта и все составляющие транспортного процесса в их взаимодействии, обеспечивает реализацию транспортно-экономических связей страны [1].

Прежде всего следует отметить, что на современном этапе развития транспортного комплекса усиление его региональных аспектов стало актуальной задачей, что полностью соответствует целям Транспортной стратегии Российской Федерации на период до 2030 года.

Региональный транспортный комплекс занимает важное место в транспортной системе страны. Например, транспорт Дагестана осуществляет большие транзитные перевозки, выполняет работу по общероссийским перевозкам грузов и пассажиров. В Рес- 
публике Дагестан на его долю приходится более 6,0 \% объема народнохозяйственных перевозок и около 5,0 \% всего грузооборота России [1].

Протяженность дорог общего пользования в Республике Дагестан на сегодня составляет 8 157,8 км, из которых 641,3 км - федерального значения, 2 478,2 км - республиканского значения и 5 038,3 км - местного значения [1].

Транспортный комплекс республики представлен всеми видами транспорта - железнодорожным, водным, воздушным, автомобильным и трубопроводным. Особая роль Дагестана в функционировании транспортной системы связана с его уникальным экономико-географическим расположением.

Железнодорожный транспорт занимает важное место в перевозках и в единой транспортной системе региона. Железнодорожный транспорт республики представлен Махачкалинским отделением Северо-Кавказской железной дороги, в структуре которой имеются объединенные подразделения. По территории республики проходят важнейшие железнодорожные маршруты федерального значения, которые связывают Россию со странами ближнего и дальнего зарубежья.

Морской транспорт. Одним из ключевых объектов транспортной инфраструктуры Северного Кавказа является Махачкалинский морской торговый порт - единственный незамерзающий порт России на Каспии, находящийся в выгодном географическом положении в зоне международных транспортных коридоров Север-Юг, Восток-Запад, с потенциально мощным нефтекомплексом. Из сухогрузов главное место занимают хлеб, лес, сульфаты, металлы, поваренная соль, рыба, хлопок, строительные материалы.

Авиационный транспорт. Основная сфера применения воздушного транспорта пассажирские перевозки. Международный аэропорт Махачкала («Уйташ»), самый южный аэропорт России, имеет стратегическое значение. Его расположение делает экономически выгодными транзитные перевозки при выполнении международных авиарейсов из Уральского и Западно-Сибирского регионов в страны Ближнего Востока. В настоящее время в аэропорту базируется авиакомпания «РусЛайн», выполняющая рейсы по многим направлениям России и зарубежья. Общая пропускная способность аэровокзала - 260 чел/час.

Автомобильный транспорт - одна из важнейших составных частей единой транспортной системы региона. Такое значение автомобильного транспорта для региона обусловлено прежде всего тем, что он обладает высокой мобильностью и возможностью доставки народнохозяйственных грузов без промежуточных перевозок, что значительно ускоряет их транспортировку и обеспечивает сохранность [1].

В настоящее время транспортный комплекс нашей республики заметно развивается, что способствует превращению Дагестана в мощный транспортный узел на юге России (табл. 1).

Таблица 1. Динамика перевозки грузов транспортом в Республике Дагестан за 2016-2017 гг.

\begin{tabular}{|l|c|c|c|}
\hline \multicolumn{1}{|c|}{ Виды транспорта } & 2017 г. & 2017 г. в \% к 2016 г. & 2016 г. в \% к 2015 г. \\
\hline $\begin{array}{l}\text { Перевозки грузов, тыс. тонн, } \\
\text { в том числе: }\end{array}$ & 178163,8 & 104,8 & 116,0 \\
\hline авиатранспорт & - & - & 106,0 \\
\hline железнодорожный транспорт & 2261,6 & 82,3 & 180,8 \\
\hline автотранспорт & 163936,7 & 106,2 & 116,2 \\
\hline водный транспорт & 198,3 & 87,4 & 32,8 \\
\hline трубопровод & 11767,2 & 92,7 & 109,4 \\
\hline
\end{tabular}


Всего за 2017 год всеми видами транспорта было перевезено 178,2 млн тонн грузов, это на 4,8 \% больше, чем в предыдущем году. Ведущее место в перевозках грузов занимает автотранспорт (92,0 \% всех перевозок). В предыдущем году вырос грузооборот по четырем видам транспорта. В частности, железнодорожным транспортом было перевезено грузов на 80,8 \% больше, рост грузооборота на автомобильном транспорте составил $16,2 \%$, а авиаперевозки увеличились на $6,2 \%$. Рост объемов перевозок авиатранспортом связан с эффективным менеджментом предоставления транспортных услуг и расширением географии полетов. В общем объеме пассажирооборота республики наибольшую долю занимали показатели железнодорожного и автомобильного транспорта.

Обеспечение стабильности и слаженности работы транспортной отрасли положительно скажется на эффективности всей экономики Дагестана, будет стимулировать снижение необоснованных затрат при перемещении грузов или пассажиров по элементам транспортной инфраструктуры, приведет к усовершенствованию технологических процессов, повысит социальную мобильность, а также производственных ресурсов и их взаимозаменяемость, будет способствовать выявлению скрытых резервов повышения эффективности деятельности транспортных предприятий.

Модернизация транспортной отрасли республики даст возможность укрепить экономическую безопасность и включить транспортную инфраструктуру региона в транснациональные системы транзитных перевозок. В свою очередь это существенно увеличит поступление денежных средств в бюджет и сократит безработицу. Проанализируем итоги финансово-хозяйственной деятельности транспорта общего пользования (табл. 2).

Из таблицы 2 видно, что за 2017 год пассажирооборот составил 1172906.0 тыс. пасс.-км и вырос на 42,1 \%. Убытки составили 8609 тыс. руб., что на 6480 тыс. руб. меньше, чем за прошлый год.

Средняя себестоимость одного пасс.-км составила 29,44 руб.

Объем услуг по перевозке грузов по всем предприятиям составил 67,5 тыс. тонн и снизился на 50,4%. Грузооборот снизился на 18,4 \%.

\section{Таблица 2. Динамика финансово-хозяйственной деятельности транспорта общего пользования Республики Дагестан за 2016-2017 гг.}

\begin{tabular}{|c|l|c|c|c|}
\hline № & \multicolumn{1}{|c|}{ Наименование показателей } & $\mathbf{2 0 1 6}$ г. & $\mathbf{2 0 1 7}$ г. & $\begin{array}{c}\text { Темпы } \\
\text { роста (\%) }\end{array}$ \\
\hline 1 & Объем работ и услуг, тыс. руб. & 98963,6 & 120012,5 & 121,3 \\
\hline 2 & Перевезено пассажиров, тыс. чел. & 61623,3 & 64585,0 & 104,8 \\
\hline 3 & Пассажирооборот, тыс. пасс.-км. & 825206,2 & 1172906,0 & 142,1 \\
\hline 4 & Перевезено грузов, тыс. т & 135,9 & 67,5 & 49,6 \\
\hline 5 & Грузооборот, тыс. т-км. & 1902,9 & 1553,1 & 81,6 \\
\hline 6 & Среднесписочная численность персонала чел. & 2474 & 2269 & 91,7 \\
\hline 7 & Сумма уплаченных налоговых платежей & 31043,6 & 33475,4 & 107,8 \\
\hline 7.1 & в федеральный & 9190,8 & 11114,4 & 120,9 \\
\hline 7.2 & в республиканский & 3203,2 & 2365,7 & 73,8 \\
\hline 7.3 & в местный & 4075,8 & 4386,4 & 107,6 \\
\hline 7.4 & во внебюджетные фонды & 14573,8 & 15608,9 & 107,1 \\
\hline
\end{tabular}




\begin{tabular}{|c|l|c|c|c|}
\hline 8 & Задолженность по платежам в бюджет & 17587,3 & 9823,3 & 55,8 \\
\hline 8.1 & \multicolumn{1}{|c|}{ в федеральный } & 5741,4 & 2080,5 & 36,2 \\
\hline 8.2 & \multicolumn{1}{|c|}{ в республиканский } & 1028,9 & 611,8 & 59,4 \\
\hline 8.3 & \multicolumn{1}{|c|}{ в местный } & 1630,9 & 882,3 & 54,0 \\
\hline 9 & $\begin{array}{l}\text { Задолженность по налоговым платежам во } \\
\text { внебюджетные фонды (всего), тыс. руб., в т. ч. }\end{array}$ & 9186,1 & 6248,7 & 68,0 \\
\hline 10 & $\begin{array}{l}\text { Субсидии (дотации) из бюджета (всего), } \\
\text { тыс. руб., в т. ч. }\end{array}$ & 116373 & 193234,5 & 166 \\
\hline 11 & Себестоимость перевозки 1-го пасс.-км & 29,44 & 32,16 & 108,2 \\
\hline 12 & Дебиторская задолженность, тыс. руб. & 24489 & 36782 & 150,2 \\
\hline 13 & Кредиторская задолженность, тыс. руб. & 58363 & 56148 & 96,2 \\
\hline 14 & Балансовая прибыль (убыток) & -15089 & -8609 & 57,1 \\
\hline
\end{tabular}

Источник: http://dagstat.gks.ru/

Снижение показателей грузовых автопредприятий связано с постоянно сокращающимся и стареющим автомобильным парком, а также с отсутствием стабильных заказов на услуги грузового автотранспорта. Рост дебиторской задолженности автопредприятий составил 50,2 \%, кредиторская задолженность снизилась на 2,8 \%. Производительность труда выросла на 26,5 \%, а средняя заработная плата - на 23,8 \%. В целом результаты анализа показывают определенный рост основных производственных показателей автопредприятий.

Важным звеном в республиканском транспортном кластере является и аэропорт Махачкалы «Уйташ». Объемы авиаперевозок пассажиров и грузов динамически связаны с экономической ситуацией в Дагестане и Российской Федерации в целом.

Основные финансово-экономические показатели перевозок авиатранспортом представлены в таблице 3.

\section{Таблица 3. Показатели финансово-экономического развития авиапредприятий Республики Дагестан}

\begin{tabular}{|l|c|c|c|c|}
\hline \multicolumn{1}{|c|}{ Наименование показателя } & $\begin{array}{c}\text { Единицы из- } \\
\text { мерения }\end{array}$ & $\mathbf{2 0 1 6}$ г. & $\mathbf{2 0 1 7}$ г. & $\begin{array}{c}\text { Темп } \\
\text { роста \% }\end{array}$ \\
\hline Объем работ и услуг & тыс. руб. & 1514251,0 & 2111998,0 & 139,5 \\
\hline Перевезено пассажиров & тыс. чел. & 262,7 & 539,9 & 137,0 \\
\hline Пассажирооборот & тыс. пасс.-км & 450124,1 & 616304,00 & 136,9 \\
\hline Перевезено грузов & тонн & 2217,6 & 2645,60 & 119,3 \\
\hline Грузооборот & тыс. т-км & 44186,40 & 60409,90 & 136,7 \\
\hline Количество самолетовылетов & ед. & 2707,0 & 3241 & 119,7 \\
\hline Среднесписочная численность & чел. & 870,0 & 899,0 & 103,3 \\
\hline Средняя зарплата & руб. & 15100,8 & 18075,0 & 119,7 \\
\hline Задолженность по зарплате & тыс. руб. & - & - & - \\
\hline $\begin{array}{l}\text { Сумма уплаченных налоговых } \\
\text { платежей в бюджеты всех уров- } \\
\text { ней }\end{array}$ & тыс. руб. & 162881,3 & 212622,4 & 130,5 \\
\hline
\end{tabular}

Источник: http://dagstat.gks.ru/

40 
В 2018 году ожидается рост спроса на услуги авиаперевозок, соответствующего доходам населения региона, на внутренних и международных авиасообщениях, который может составить 444,7 тыс. пассажиров на внутренних и 80,6 тыс. пассажиров на международных авиасообщениях [9].

С учетом факторов, влияющих на объем авиаперевозок, для выполнения необходимых экономических, инженерных и технических расчетов модернизации Махачкалинского аэропорта «Уйташ» за базовый вариант взят реалистичный прогноз авиаперевозок, предполагающий положительную динамику объемов обслуживания авиапассажиров с 2017 по 2022 годы с темпами прироста в пределах 6,0-7,2 \% внутренних авиаперевозок и 5,0-6,5 \% - международных.

Автотранспорт в условиях Дагестана, где нет развитой сети железных дорог и малой авиации, играет важную роль в обеспечении внутриреспубликанских перевозок. В общем объеме всех перевозок, осуществляемых транспортной отраслью, доля автотранспорта составляет около 90 \%. Таким образом, автотранспорт имеет не только хозяйственное, но и социально-политическое значение для республики.

В республике под автодороги занято 21,1 тыс. га земельной площади, это около $1 \%$ территории региона.

Сегодня почти все районные центры и города соединены регулярным автобусным сообщением со столицей республики.

\section{Таблица 4. Динамика пассажирооборота транспорта общего пользования РД}

\begin{tabular}{|l|c|c|c|}
\hline \multicolumn{1}{|c|}{ Показатели } & 2017 г. & $\begin{array}{c}2017 \text { г. в \% к } \\
2016 \text { г. }\end{array}$ & $\begin{array}{c}\text { Справочно: 2016 г. в \% } \\
\text { к 2015 г. }\end{array}$ \\
\hline $\begin{array}{l}\text { Пассажирооборот всего, } \\
\text { млн пасс.-км, в том числе: }\end{array}$ & 5001,9 & 95,7 & 98,9 \\
\hline авиатранспорт & - & - & 87,7 \\
\hline железнодорожный транспорт & 322,4 & 99.4 & 86,8 \\
\hline автотранспорт & 4672,0 & 108,3 & 101,6 \\
\hline электротранспорт & 7,5 & 107,1 & в 2,8 p \\
\hline
\end{tabular}

В общем, в 2017 году всеми видами транспорта было осуществлено пассажирских перевозок объемом 5001,9 млн пасс.-км, это на 4,3 \% ниже уровня предыдущего года. Доля пассажирских перевозок посредством автотранспорта составила 93,4 \%. Электротранспортом за 2017 год было осуществлено пассажирских перевозок объемом 7,5 млн пасс.-км, это на 7,1 \% больше, чем в предыдущем году. Доля пассажирских перевозок, осуществленных посредством автотранспорта, составила 98,2 \%.

В ходе реализации Федеральной целевой программы транспортной стратегии Российской Федерации на период до 2030 года планируется построить портовый железнодорожный сортировочный комплекс морского порта Махачкалы, в который будут инвестированы финансовые средства из федерального бюджета общим объемом 100 млн руб. В него войдут железнодорожные пути, по которым будут осуществляться приемка, сортировка и отправка составов, средства автоматизации и централизации [8].

За счет того, что Дагестан занимает ключевое геостратегическое положение и имеет прямой выход к морю (по суше и по морю он граничит со странами ближнего и дальнего зарубежья - Азербайджаном, Грузией, Казахстаном, Туркменистаном, Ираном), Россия может приобрести ряд преимуществ, обеспечив стабильное и безопасное железнодорожно-паромное сообщение в Каспийском бассейне. Это укрепит позиции 
России в системе международных транспортных перевозок и создаст основы транспортной логистики Центральная Азия - Россия - Украина - Балканские страны, а также обеспечит реальный противовес следующим в обход российской территории маршрутам.

По завершении программы реконструкции и строительства порта объемы доставки продукции по транспортному коридору Север-Юг увеличатся вдвое. Махачкалинский порт является стратегически важным звеном транспортной системы региона, связывающим Россию с государствами Каспийского бассейна. Этот проект имеет геополитическое значение: он предусматривает создание на Каспии сбалансированного и устойчивого транспортно-технологического кластера, который объединит в единый мультимодальный комплекс портовые сооружения, железнодорожный и морской транспорт.

На основе проведенного анализа можно сделать вывод: в целом адаптация транспорта к современным рыночным условиям в регионе проходит успешно. Тем не менее, реальное состояние отрасли, уровень и темпы ее развития сложно считать удовлетворительными на данном этапе. Негативное воздействие на развитие транспортной системы оказывает ряд актуальных проблем и противоречий, формирующих системную проблему транспортной отрасли: несоответствие между низким уровнем ее развития, эффективностью и качеством функционирования и возрастающим спросом экономики и общества на транспортные услуги. К таким проблемам относятся:

- плачевное состояние опорной транспортной сети, не соответствующее существующим и перспективным грузо- и пассажиропотокам;

- отсутствие отвечающих современным требованиям технологий, способных удовлетворить растущий спрос на транспортные услуги высокого качества, снизить себестоимость перевозок, оптимизировать использование существующей транспортной инфраструктуры;

- отсутствие отвечающих потребностям населения доступных и качественных транспортных услуг. Общественный транспорт городского и пригородного сообщения не способен удовлетворить спрос на качественные пассажирские перевозки;

- существенное отставание в динамике развития дорожной сети от автомобилизации общества. Сегодня треть протяженности федеральных автодорог эксплуатируются в режиме перегрузки, особенно на подходах к крупным городам и рекреационным зонам;

- недостаточные темпы обновления основных фондов всех видов транспорта, в результате чего их износ составляет от 55 до 70 \% и продолжает нарастать. Это снижает уровень безопасности, ведет к росту транспортных издержек и возникновению дефицита провозных, пропускных и скоростных возможностей отдельных элементов транспортной системы;

- сохраняющаяся некоторая зависимость внешнеторговой деятельности от иностранных коммуникаций и перевозчиков. Транзитный потенциал Республики Дагестан, мощность портовой инфраструктуры которой позволяет обеспечивать переработку внешнеторговых грузов, используется не в полной мере;

- низкий уровень безопасности транспортного процесса, прежде всего дорожного движения.

- значительное обострение проблем обеспечения антитеррористической устойчивости транспортной системы.

Проведенный научно-практический анализ показал, что в условиях имеющегося экономического роста транспортный комплекс региона в целом в минувшем году рабо- 
тал устойчиво. Вместе с тем, как свидетельствует анализ, по ряду позиций ситуация остается крайне напряженной. Например, в серьезные экономические потери для региона выливаются проблемы взаимодействия отдельных видов транспорта. Модернизация транспортно-логистического комплекса республики невозможна без создания эффективной системы взаимодействия всех видов транспорта и логистики. Только при создании комплексных логистических моделей, которые включают все виды транспорта, можно достичь наибольшего удобства, скорости и экономии при доставке груза.

Недопустимого уровня достигает транспортное неравенство, то есть различия в транспортном обслуживании районов Южного федерального округа и проживающего в них населения.

Необходимо отметить, что в регионе остаются населенные пункты, не обеспеченные постоянной круглогодичной связью с транспортной сетью общего пользования по автомобильным дорогам, имеющим твердое покрытие.

В Послании Президента РД говорится, что многие министерства, в том числе промышленности, транспорта и связи, теряют время, инвестиции, упускают возможности, которые имеются для серьезного прорыва в развитии экономики [11].

Необходимо повышать технический уровень транспортных средств региона, а также применять современные перевозочные, управленческие и информационнотелекоммуникационные технологии. Очевидно, что без этого нельзя рассчитывать на эффективность функционирования и конкурентоспособность нашей региональной транспортной системы в целом.

Надежная сеть автодорог способствует бесперебойной связи между регионами, снижению транспортных издержек и улучшению качества оказываемых услуг.

\section{Литература}

1. Дайзиев Д.А., Исаева Ш.М. Транспортный комплекс Республики Дагестан // Стратегия развития Северного Кавказа: новый взгляд на решение проблем. Материалы Всероссийской научно-практической конференции аспирантов, магистрантов и студентов. - Пятигорск, 2015. - С. 406-410.

2. Катаева Ю.В. Интегральная оценка уровня развития транспортной инфраструктуры региона // Вестник Пермского университета. - 2013. - Вып. 4 (19).

3. Курнышева Н. Транспортный комплекс и модернизация // Экономист. - 2012. № 5. - C. 33-39.

4. Распоряжение правительства Российской Федерации от 22 ноября 2008 г. № 1734-р «О транспортной стратегии Российской Федерации на период до 2030 года».

5. Руцик Ю. Инновации в сфере транспортных услуг // Экономика возрождения России. -2011 - № 4.

6. Хизриева 3.A. Организационные аспекты повышения эффективности работы предприятий городского пассажирского автотранспорта // Региональные проблемы преобразования экономики. - 2010. - № 2. - С. 75-82.

7. Стенографический отчет о заседании Президиума Государственного Совета по вопросам развития транспортной инфраструктуры страны // www.kremlin.ru.

9. http://dagstat.gks.ru/.

10. http://www.gks.ru/.

11. http://www.rgvktv.ru/news/13914.

Поступила в редакцию 10 декабря 2018 г. 
UDC 656.13

DOI: $10.21779 / 2500-1930-2018-33-4-37-44$

\title{
The analysis of the transport complex state and prospects for its development in the Republic of Dagestan
}

\begin{abstract}
Sh.M. Isaeva
Dagestan State University, Russia, 367001, Makhachkala, M. Gadzhiev st., 43a;shamsi69@rambler.ru

In the context of economic transformations and the need to develop under the influence of the ongoing crisis, sanctions pressure and globalization, the transport complex becomes a key factor in achieving the economic and social goals of the country, as it is a link uniting all regions and various sectors of economy into a single economic space, ensuring their mutual coordinated activity. To solve the problems of growth of the region's economy as a part of the country's economy, it is necessary to ensure smooth functioning of the entire infrastructure in the transport industry of Dagestan, to improve the quality and mobility of its services.

The problem of studying the transport complex, the issues of its formation and development, as well as its content itself is multifaceted. Let us focus on the main aspects of the impact of the transport system on the economic development and quality of life in the region. For this purpose, the article presents a study of the state in structural elements in the transport industry in the Republic of Dagestan, considering a number of issues of its functioning and development prospects, the analysis of statistical indicators for the period of 2015-2017, the results of which revealed a correlation between the state of the transport complex and the economy of the region, confirming the thesis on the primacy of the transport industry in the implementation of the Transport strategy of the Russian Federation.
\end{abstract}

Keywords: transport, economy, analysis, investment, dynamics, mobility, quality, infrastructure, length, industries.

Received 10 December, 2018 